\title{
Axially loaded grouted connections in offshore conditions using ordinary portland cement
}

\author{
P. Schaumann, J. Henneberg* and A. Raba \\ Institute of Steel Construction, Gottfried Wilhelm Leibniz Universität Hannover (LUH) - ForWind, Germany \\ *corresponding author, e-mail address: henneberg@stahl.uni-hannover.de
}

\begin{abstract}
A grouted connection (GC) is a hybrid connection which joins two telescoped steel tubes by filling the annulus between the steel tubes with grout. GCs are frequently used to enable a force fitted connection between piles and substructure of offshore wind turbines. At latticed substructures this connection is located at mudline level in wet ambient conditions (AC). Nowadays special grout materials are used to achieve not only best mechanical properties but also a good performance during grouting in offshore conditions.

To reduce production costs the use of ordinary portland cement (OPC) is investigated as an alternative filling material within this paper. OPC has a much lower tendency to segregate, as there are no aggregates added. This leads to more simplified, stable and cheaper production processes offshore. Further focus is put on the failure mode of OPC filled GCs in submerged condtions.

For an appropriate use of OPC offshore a feasible mechanical performance needs to be ensured. Investigating this, small and large-scale laboratory tests were performed at Leibniz Universität Hannover. Using the experimental test setup of previous investigations for special high performance grouts (HPG) [1,2], enables a direct comparison of HPG and OPC. Documenting liquid and solid OPC properties, like slump flow and compressive strength confirms a stable material quality. Small-scale ULS-tests showed significantly lower ULS-capacities and a more brittle failing process compared to HPG. Lagre-scale tests confirmed the observed failure mechanisms of Schaumann and Raba for OPC filled GCs in submerged conditions [3]. Carried out tests showed significant influence of grout material and confirmed influence of grout annulus size on fatigue capacity.
\end{abstract}

Keywords: Grouted Connection; Ordinary Portland Cement; Axial Loading; Fatigue; Submerged.

\section{Introduction}

A grouted connection (GC) is a composite connection of two steel tubes with different diameter. A smaller steel tube (pile) is plugged into a steel tube with larger diameter (sleeve). The annulus between these steel tubes is filled with an offshore specific grout material. To ensure a distinct interlocking, the steel surfaces in direction of the annulus are profiled with weld beads (shear keys) (cf. Fig. 1).

This type of connection is used to realise a force fitted connection between foundation piles and typically lattice substructures of offshore wind turbines, such as the jacket shown in Fig. 1.
Wave and wind loading lead to bending moments at the tower base. These are transferred by axial force couples into the foundation piles. Consequently GCs in lattice substructures are predominantely loaded by variable axial forces. Inside the connection the axial forces lead to concentrated compressive stresses $\left(\sigma_{\text {strut }}\right)$ between two opposing shear keys. Depending on the shear keys position different strut inclination angles $\alpha$ occur; see Fig. 1. The radial load transfer results in tangential stresses $\left(\sigma_{\text {tangential }}\right)$ in circumferential direction. 


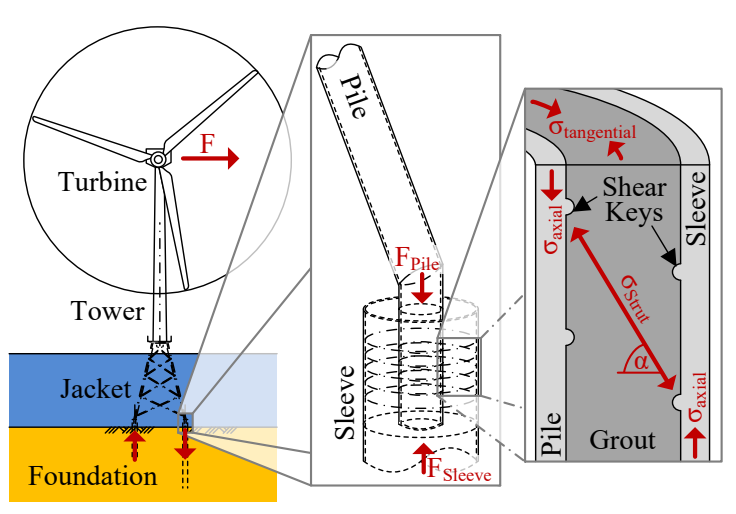

Fig. 1. Lattice substructure of an offshore wind turbine (left)with a detail of a grouted connection (centre) and its load bearing behaviour (right)

The previously described load bearing behaviour can lead to two major degradation mechanisms. On the one hand, shear cracking can occur along the compression struts (cf. Fig. 2 ). On the other hand, shear keys cause local stress concentrations in the grout material which can lead to local crushing. In dry ambient conditions the crushed material leads to a more homogenous load distribution at the shear keys and thereby a lower stress concentration. In connections with submerged ambient conditions (AC), water can enter the grout annulus by local cracks and bond loss gaps in interfaces [3]. Variable loading causes a pumping effect in cracks and interfaces. At the shear keys locally crushed material is flushed out of the connection. Consequently, step by step the pile is pushing through the grout. Fig. 2 shows a grouted connection after 200'000 load cycles and voids resulting from washed out grout material around the shear keys. Connection failure occurs over a large amount of load cycles.

Design methods for axially loaded GCs are only validated for a defined amout of geometrical and mechanical parameters as well as dry ambient conditions (cf. [4] and [5]). Thus, the research project 'GROWup' was realised at Leibniz Universität Hannover to investigate large grout annuli, HPG and OPC under realistic submerged AC. This paper focuses on the load bearing behaviour of OPC filled GCs as alternative for high performance grouts.

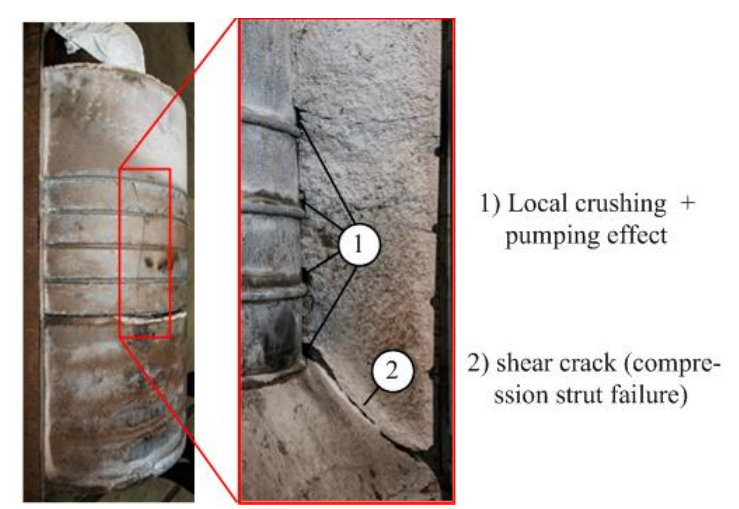

Fig. 2. Failure modes of $G C$ in submerged ambient conditions (grout material: Densit Ducorit S5)

In contrast to most experimental test set-ups, which are basis for current offshore guidelines, like Billington [6, 7] and Ingebrigtsen [8], the done tests are realised with realistic submerged ambient condition (cf. Fig. 3 and 11). In previous work this test-setup was developed by Schaumann and Raba to investigate the influence of water on the load bearing capacity and behavior of GCs with HPG [9].

\section{Grout material}

Different OPCs were tested for material strength, hydration heat development, tendency to crack and shrinkage by the Institute of Building Material Science (LUH) [10]. Holcim Aqua4 (CEM III/B 42.5 LLH/SR/NA) showed most suitable material properties for its use in offshore conditions.

In order to document the OPC's material characteristics, samples for cube and prism strength were taken in parallel with the grouting process of the GC specimens.

In contrast to offshore installations the grouting process of the presented tests occured in ideal laboratory conditions. After 24 hours of hardening the specimens were stored in submerged condition. With 28 days of hardening the following material parameters were assessed:

$$
\begin{array}{rrr}
\mathrm{f}_{\mathrm{c}} & = & 60 \mathrm{MPa} \\
\mathrm{E}_{\text {stat }} & = & 177^{\prime} 250 \mathrm{MPa} \\
\mathrm{E}_{\text {dyn }} & = & 19^{\prime} 900 \mathrm{MPa}
\end{array}
$$

\section{Small-scale tests}

\subsection{Test set-up}

Within the research project 'GROWup' a small-scale test set-up was developed to enable 
submerged AC. To ensure reproducibility the same test rigs and specimen dimensions from previous investigations with high performance grout (BASF Masterflow 9500, $\mathrm{f}_{\mathrm{cu}}=144.1 \mathrm{MPa}$ and Densit Ducorit S2, $\mathrm{f}_{\mathrm{cu}}=116.3 \mathrm{MPa}$ ) were used for OPC.
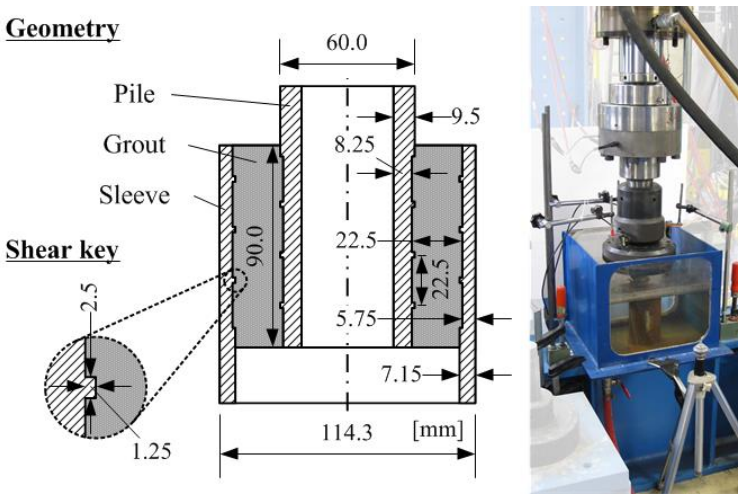

Fig. 3. Geometry of small-scale GC (left) and test rig with water basin for submerged ambient conditions (right)

A cyclic compession-compression load in axial direction was generated by a servohydraulic press. Bending moments due to eccentricities were avoided by an axial hinge in the test rig.

\subsection{Ultimate Limit State (ULS)}

Within the ULS-tests a quasi-static load was increased until a maximum axial displacement of $\mathrm{u}_{\max } \approx 8 \mathrm{~mm}$ was reached.

Fig. 4Fig. 9 shows the load-displacement behaviour due to quasi static loading. At the beginning of the ULS-tests initial crushing occured at a low loading (marked with red color). After this initial crushing, which was observed for all small-scale ULS-tests with OPC, the specimens acted linear elastic until $F_{\text {elast }}$ was reached. With $F_{\text {elast }}$ a non-linear plastic behavior of the specimen started with significant loss of stiffness. Exceeding $\mathrm{F}_{\mathrm{ULS}}$ a stable postfailing behaviour began.

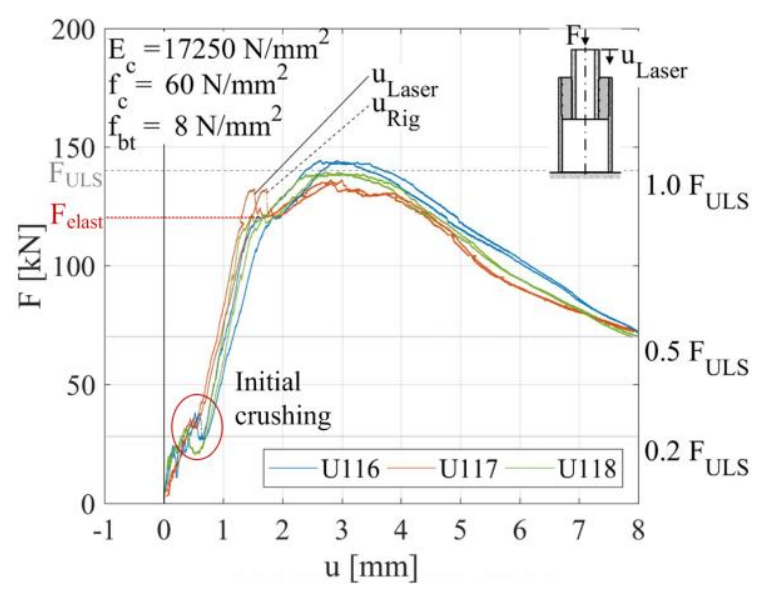

Fig. 4. Load displacement behaviour of ULS-tests with OPC (Holcim Aqua4)

Comparing the ULS-failure of Holcim Aqua4 and Densit Ducorit S2 (cf. Fig. 5), shows a more brittle behaviour of a GC with OPC.

$$
\begin{array}{ll}
\mathrm{F}_{\text {elast }} / \mathrm{F}_{\text {ULS }} \text { 1:1.2 } & \text { (Holcim Aqua4) } \\
\mathrm{F}_{\text {elast }} / \mathrm{F}_{\text {ULS }} \text { 1:1.4 } & \text { (Densit Ducorit } \mathrm{S} 2 \text { ) }
\end{array}
$$

Besides a more brittle behaviour, the ultimate strength of GCs with OPC was significantly lower then expected from the material strength ratio of Holcim Aqua4 and Densit Ducorit S2 [10].

$$
\begin{aligned}
& \mathrm{F}_{\text {ULS }}: 140 \mathrm{kN} / 543 \mathrm{kN} \approx 1: 4 \\
& \mathrm{f}_{\mathrm{c}}: \quad 60 \mathrm{MPA} / 118 \mathrm{MPa} \approx 1: 2
\end{aligned}
$$

One reason might be the lower interlocking inside the cracks, as OPC has no aggregates added. When it comes to cracking a lower remaining connection strength is left.

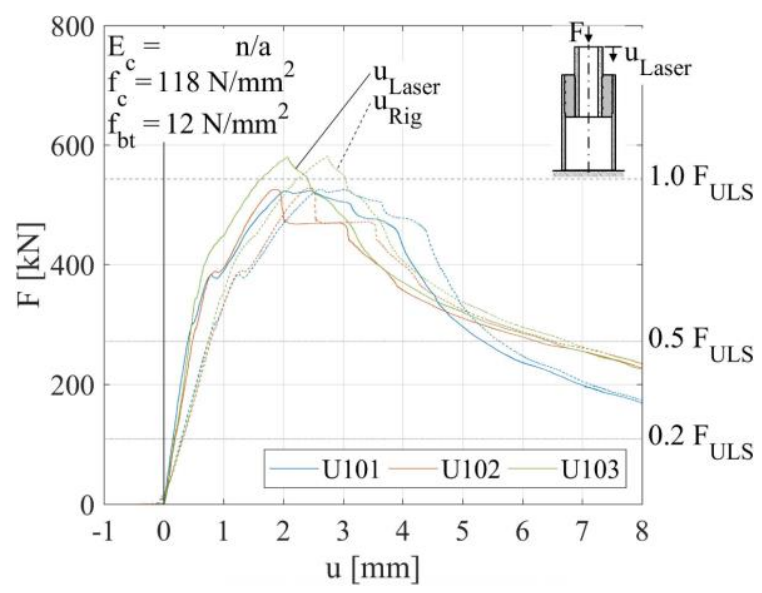

Fig. 5. Load displacement behaviour of ULS-tests with Densit Ducorit $S 2$

The dismantled test specimen in Fig. 6 confirms the previously detected brittle failing 
behaviour of OPC. Especially the left side depicts a huge amount of diffuse cracks beside the typical shear cracks along the compression struts (white), spread all over the grout layer. Compared to Fig. 7 cracking OPC leads to sharpedged, clean fragments. This effect results from the lack of aggregats and thereby a very homogenous material.

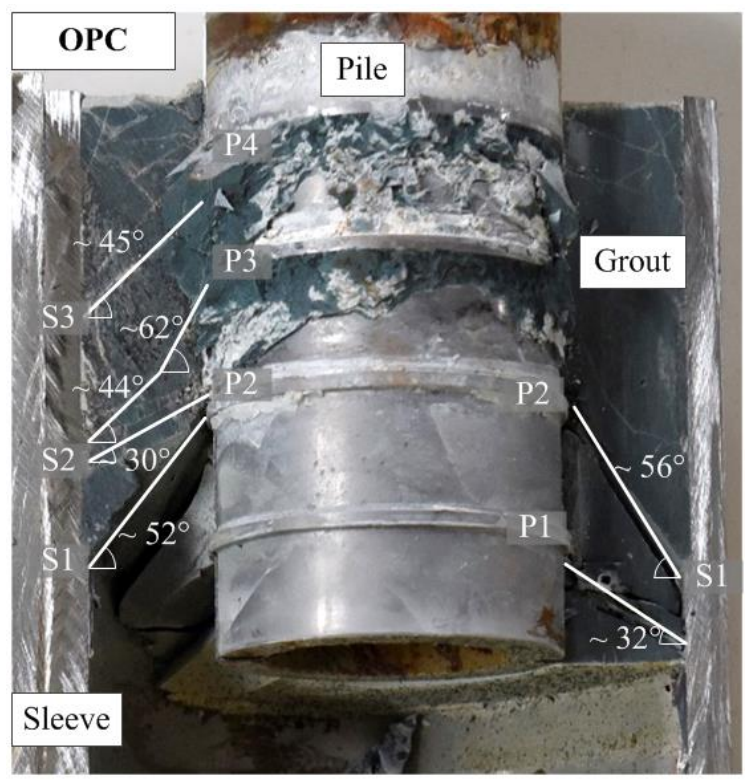

Fig. 6. Dismantled specimen with Holcim Aqua4 $\left(F_{\max }=50 \% F_{U L S}, f=5 \mathrm{~Hz}, A C:\right.$ wet $)$

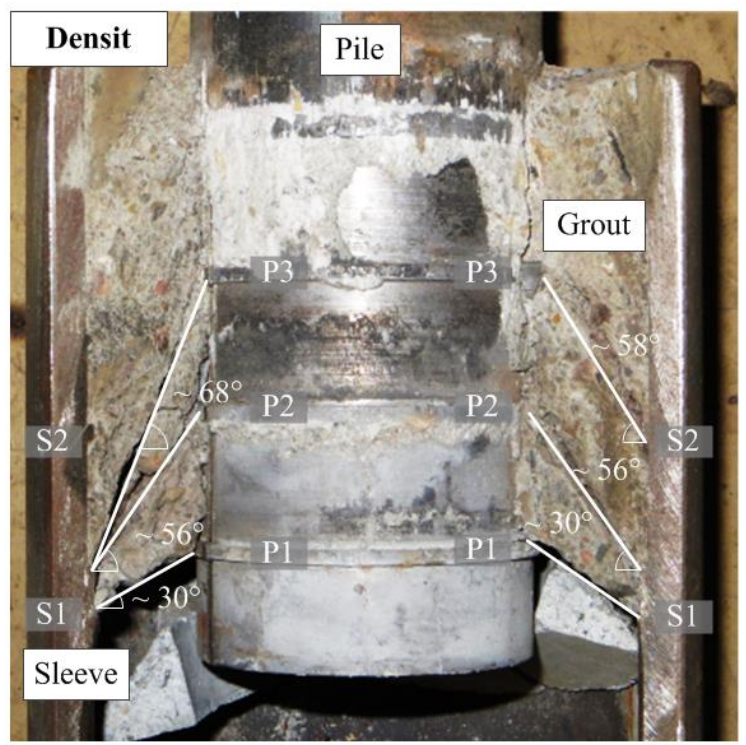

Fig. 7. Dismantled specimen with Densit Ducorit $S 2\left(F_{\max }=50 \% F_{U L S}, f=5 \mathrm{~Hz}, A C\right.$ : wet $)$

\subsection{Fatigue Limit State (FLS)}

In comparison to the ULS-tests the fatigue tests are realized under dry and submerged AC. According to the ULS strength constant amplitudes of $0.2 \mathrm{~F}_{\mathrm{ULS}}$ and $0.5 \mathrm{~F}_{\mathrm{ULS}}$ were applied until failure. Dry tests showed significantly higher fatigue strength than tests under submerged AC (cf. Fig. 8). The fatigue strength shows huge scatter and no feasible coherences to generate an S-N-curve for this kind of GC. Therefore, more tests are needed to be statistically secured. Scale effects might have a huge influence on the results.

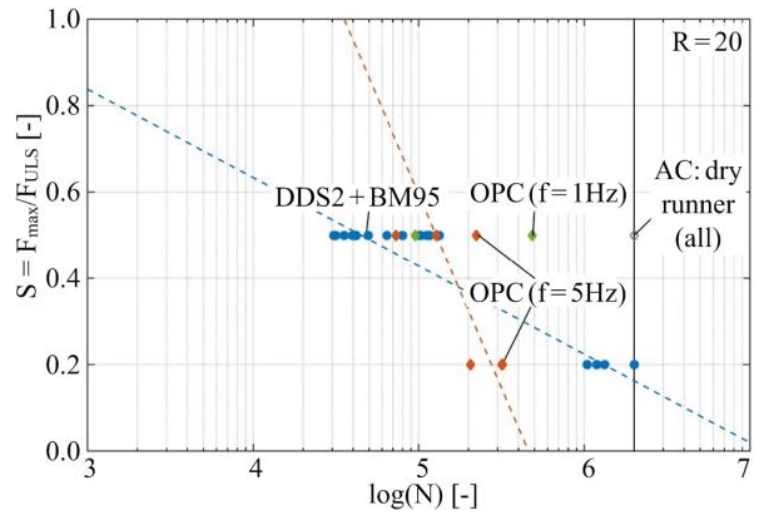

Fig. 8. S-N-curve of small-scale tests (Geom 1)

Analyzing the failure mode showed good accordances to GCs filled with high performance grout [8]. Flushing of locally crushed OPC and shear failure along the compression struts was observed.

\section{Large-scale tests}

\subsection{Test set-up}

A further investigation of 'GROWup' was the development of a large-scale test set-up for submerged ambient conditions (cf. Fig. 11) to reduce scale effects and install more detailed measurement systems. Thereby two different test specimens G1 and G2 with large grout annulus were investigated. Same test set-up was used for OPC to have a direct reproducibility between HPG and OPC.

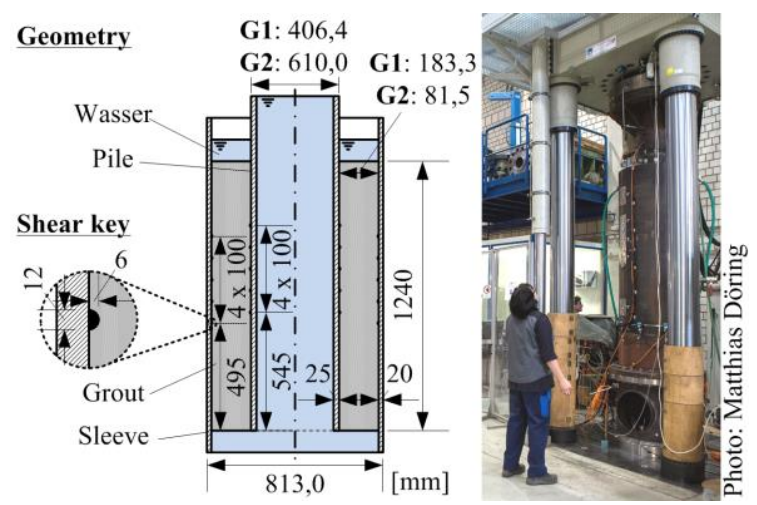

Fig. 9. Test setup of the large scale GC (submerged ambient condition) 
Different to common fatigue tests a stepwise constant amplitude of compression-compression loading was applied. With each 100'000 load cycles (one step) the cyclic axial load was increased by $250 \mathrm{kN}$. A stepwise increasing fatigue test approximates the state of fatigue failure, as initial damage from lower load stages cannot be quantified. However different load stages can be analised with a low amount of tests. The damage of the GC was defined by the relative axial displacement between pile and sleeve.

\subsection{Results}

The displacement behaviour of specimen G1 is shown in Fig.10. After a linear elastic behaviour (no degradation) in the first load step, a small degradation of $0.4 \mathrm{~mm}$ axial relative displacement occured in load step $2\left(2 \times 10^{-6}\right.$ $\mathrm{mm}$ (cycle). Further load increase to $750 \mathrm{kN}$ led to a significant degradation growth of $1.7 \mathrm{~mm}$ in load step $3\left(1.7 \times 10^{-5} \mathrm{~mm} /\right.$ cycle $)$; the degradation had quadruplicated. As guidelines do not suggest termination criterions (TC) for fatigue tests of $\mathrm{GC}$ these tests were terminated at relative displacements between pile and sleeve of $\mathrm{u} \approx 2$ $\mathrm{mm}$ and a continuous degradation per load cycle (cf. Fig.10). Executing the test procedure at an earlier stage of degradation compared to previous investigations of Schaumann and Raba (terminated at $\mathrm{u} \approx 25 \mathrm{~mm}$ ) [2] should give information on the chronology of compression strut failure and local crushing on fatigue damage initiation.

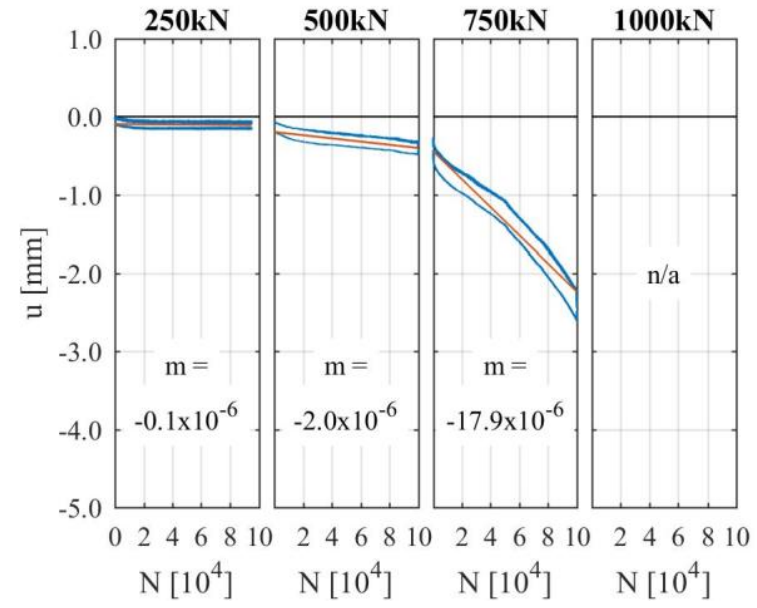

Fig.10. Relative axial displacement $u$ between pile and sleeve of specimen $G 1$

Specimen G2 with a smaller grout annulus of $\mathrm{t}_{\mathrm{g}}=81.5 \mathrm{~mm}$, had more then twice the fatigue capacity of the specimen G1. Approximatly the same amount of displacement and thereby degradation was reached finishing load step 7 $(1750 \mathrm{kN})$. Detailed data is shown in Fig. 11. Compared to G1 the linear elastic behaviour enlarged to load step 4 in G2. In load step 5 and 6 small degradative effects were observed. However no continuous degradation occurred. In load step 7 the degradation switched to a continuous pushing through. The test was terminated.

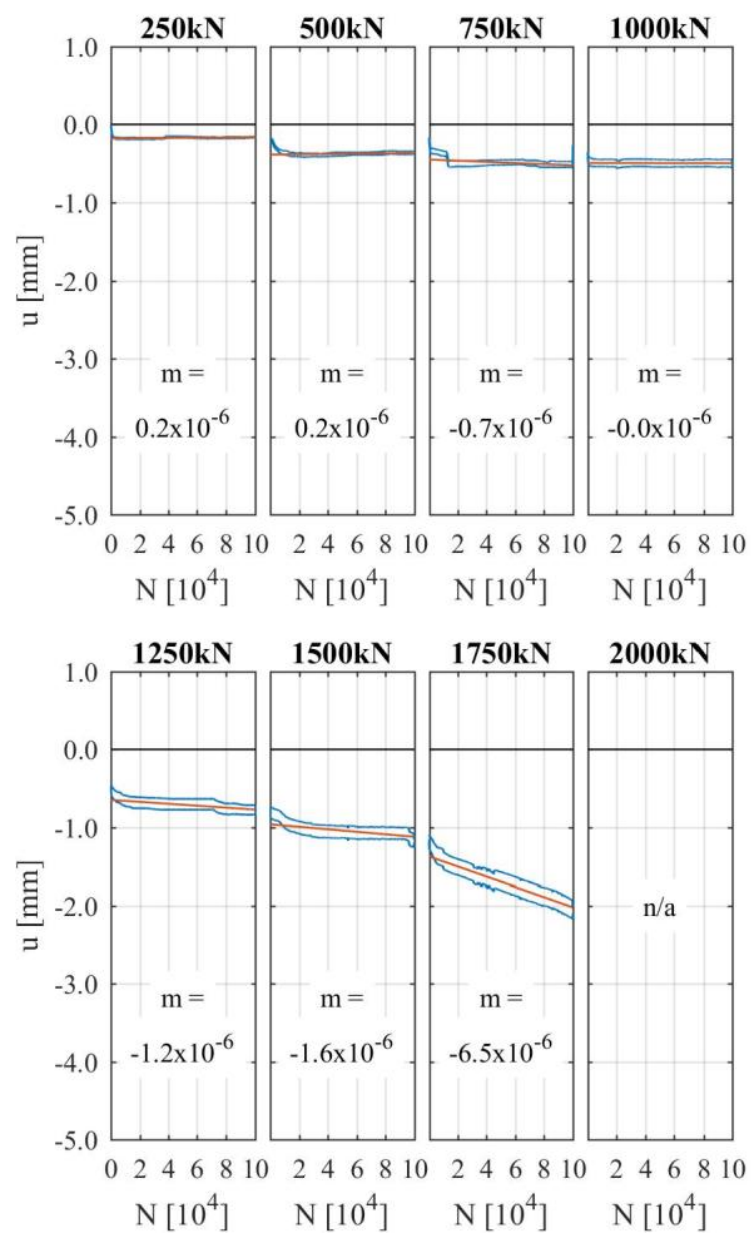

Fig. 11. Relative axial displacement $u$ between pile and sleeve of specimen $G 2$

Exemplarily the dismantled specimen of G1 is shown in Fig. 12. Opening the tested specimens, showed a mostly intact grout annulus, with two cracks in horizontal direction at the top and bottom end off the shear key area (sleeve side). Additionally, local grout crushing at the pile's shear keys occurred. In addition some micro cracks were observed scattered over the grout layer. Their influence on the fatigue capacity is assumed to be negligible. The measured relative axial displacement (cf. Fig.10) coincides with the void area at the shear keys. Concludingly, local crushing at the shear keys is 
decisive for the fatige capacity of GC filled with OPC under submerged conditions.
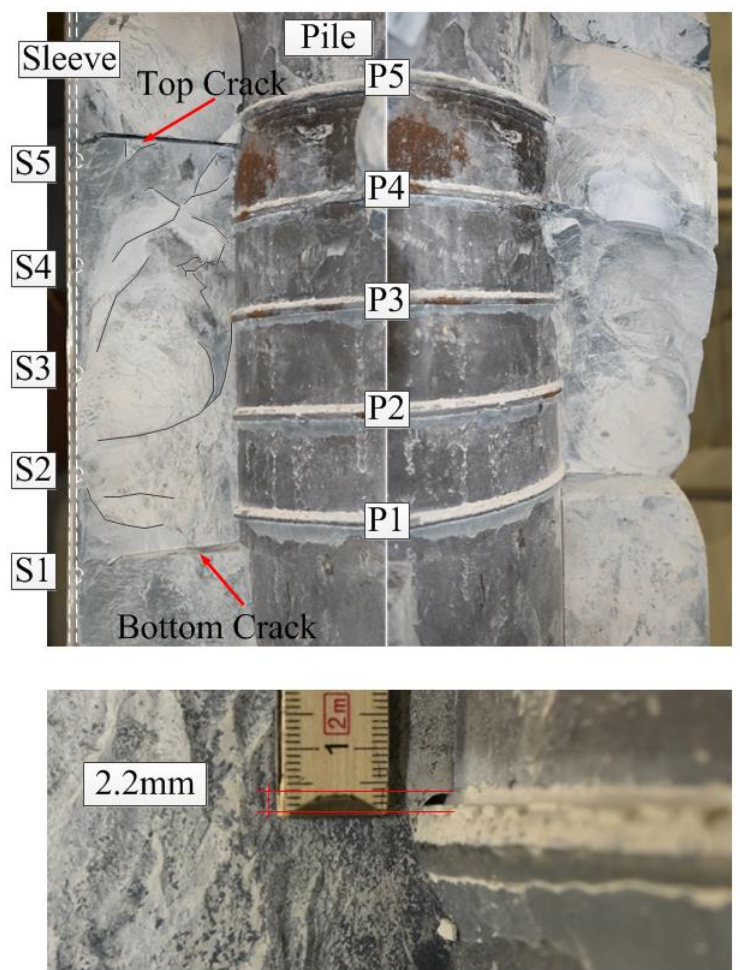

Fig. 12. Dismantled specimen G1 (top) and enlarged crushing detail at shear key (bottom)

A quantitative comparison of OPC and HPG for GCs is not possible from the tests carried out. Different to the tests with OPC previous test configurations were performed with load steps of $1 \mathrm{MN}$. Despite different load step sizes, comparing same amounts of degradation per cycle, a ratio of fatigue capacity between OPC and HPC is prognosed.

Table 1. Comparison of fatigue capacity of $G C$ with Densit Ducorit and Holcim Aqua4

\begin{tabular}{ccc} 
Specimen & $\begin{array}{c}\text { Degradation } \\
{[\mathbf{m m} / \mathbf{c y c}]}\end{array}$ & $\begin{array}{c}\text { Axial load } \\
{[\mathbf{M N}]}\end{array}$ \\
\hline DD G1 & $-2.5^{*} 10^{-6}$ & 1 \\
DD G2 & $-6.7^{*} 10^{-6}$ & 3 \\
HA4 G1 & $-2.0^{*} 10^{-6}$ & 0.5 \\
HA4 G2 & $-6.5^{*} 10^{-6}$ & 1.75 \\
\hline
\end{tabular}

By reference to Table 1 the fatigue strength ratio $F S R \approx 2$ is approximatly the same as the material strength ratio $M S R \approx 2$.

\section{Conclusion and outlook}

In this paper results of small and large-scale tests of axially loaded grouted connections with ordinary portland cement (OPC) were presented. Thereby the load-bearing behaviour under quasistatic and cyclic axial loading was analysed and compared to grouted connections with high performance grouts (HPG).

Compared to HPG small-scale ULS-tests with OPC showed a significantly reduced ultimate limit strength $\left(\mathrm{F}_{\mathrm{ULS}, \mathrm{OPC}} / \mathrm{F}_{\mathrm{ULS}, \mathrm{HPG}} \approx 1: 4\right)$ thereby initial crushing and a more brittle connection failure was identified. Reasons for this might be reduced interlocking of crack surfaces due to missing aggregates and a significantly lower material strength of the grout material.

The fatigue behaviour of OPC filled GCs under axial cyclic compression loading was similar to HPG filled GCs. The small amount of realised large-scale tests showed tendentially proportional correlation between material strength and connection strength. The next step would be to develop a generic ultimate limit criterion for grouted connections under submerged conditions. Therefore, further investigations are needed. On the one hand, the degradation development under large axial displacements has to be investigated due to expected nonlinear damage progression. On the other hand, the degradation leads to stiffness loss in the jacket chords and thereby can influence the global load-bearing behaviour of the total substructure.

On basis of the tests carried out OPC seems to be a suitable alternative to high performance grouts. Due to reduced connection strength the grout length has to be increased and more shear keys are needed to achieve comparable fatigue resistances.

\section{Acknowledgement}

The presented results were achieved within the research project 'GROWup - Grouted Joints for Offshore Wind Energy Converters under reversed axial loadings and upscaled thicknesses' funded by the German Federal Ministry for Economic Affairs and Energy (BMWi, funding sign: 0325290). The research partners were Institute for Steel Construction and Institute of Buildung Material Science, both at Leibniz Universität Hannover, Germany. The 
authors thank the BMWi for funding and all accompanying industry project partners (DNV GL, Senvion SE, Siemens Wind Power, Wilke \& Schiele Consulting $\mathrm{GmbH}$ ) for their support. Additionally the authors thank the material manufacturers for their support. Concluding thanks goes to Prof. Lohaus and his team from the Institute of Building Material Science for an excellent project collaboration.

\section{References}

[1] Bechtel B. Fatigue Behavior of Axially Grouted Connections in Jacket Structures. Leibniz Universität Hannover, Institute for Steel Construction. Dissertation; 2016.

[2] Schaumann P, Raba A, Bechtel A. Fatigue Behavior of Grouted Connections at Different Ambient Conditions and Loading Scenarios. Proceedings of $14^{\text {th }}$ Deep Sea Offshore Wind R\&D Conference. Trondheim; 2017.

[3] Schaumann P, Raba A, Bechtel A. Impact of Water on the Fatigue Performance of LargeScale Grouted Connection Tests. Proceedings of the $35^{\text {th }}$ International Conference on Ocean Offshore and Arctic Engineering OMAE. Busan South Korea; 2016.

[4] DIN EN ISO 19902. January 2014. Petroleum and natural gas industries - fixed steel offshore structures. DIN Deutsches Institut für Normung e.V..
[5] DNVGL-ST-0126. April 2016. Support structures for wind turbines. DNV GL AS.

[6] Billington C J, Chetwood J. Lessons from Previous Research for the Design of Grouted Connections for Offshore Wind Foundations. Proceedings of the International Quality \& Productivity Center Conference. Houston Texas USA; 2012.

[7] Billington CJ, Tebbet I E. The Basis for New Design Formulae for Grouted Jacket to Pile Connections. Proceedings Offshore Technology Conference; 1980

[8] Ingebrigtsen T, Løset Ø, Nielsen S G. Fatigue Safety and Overall Safety of Grouted Pile Sleeve Connections. Proceedings of the 22nd Annual 1990. Houston Texas USA; 1990

[9] Schaumann P, Raba A, Bechtel A. Axially loaded grouted connections in fatigue tests. Proceedings of HiPerMat $4^{\text {th }}$ International Symposium on Ultra-High Performance Concrete and High Performance Construction Materials. Kassel Germany; 2016

[10]Cotardo D, Lohaus L, Werner M. Usability Proof of Ordinary Portland Cement as a Grout Material for Offshore Wind Turbines. in Proceedings of the 26th ISOPE. Rhodes Greece 2016.

[11]Schaumann P, Raba A, Bechtel A. Effects of attribution due to water in cyclically loaded grouted joints. Proceedings of the $33^{\text {th }}$ International Conference on Ocean. Offshore and Arctic Engineering OMAE. San Francisco California USA; 2014 